\title{
Harmonic Reduction of Arc Furnaces Using D-Statcom
}

\author{
S.Pushpavalli, A. CordeliaSumathy \\ 1. PG Scholar, Francis Xavier Engineering College,Vannarpettai,Tirunelveli \\ 2. Associate Professor, EEE Department, Francis Xavier Engineering College,Tirunelveli
}

\begin{abstract}
Arc furnaces are used in industries for induction heating and welding. Due to the rapid growth of nonlinear loads, such as power electronic control equipments and Electric arc furnace (EAF) power quality problems such as harmonics and voltage flicker are introduced in the power system. It occurs because of the time-varying and non-linear behaviour of the electric arc furnace operation. Hence an Electric arc furnace model is needed to analyze the power quality. In this paper, a time domain model called hyperbolic model for electric arc furnace is analyzed using MATLAB. The model is used to study its behaviour on the power system using MATLAB. To improve the power quality D-STATCOM is proposed, in which the control strategies used are Direct, Indirect control and Hysteresis controller. Direct control technique uses P-Q theory in which transformation is based on orthogonal reference frame. Indirect control technique uses d-q theory in which transformation is based on synchronous reference frame. Hysteresis controller uses Hysteresis Bandwidth to produce the switching signals.

Control strategies used in D-statcom are simulated using MATLAB/SIMULINK.
\end{abstract}

\section{INTRODUCTION}

Usage of EAF results in voltage fluctuation which leads to the reduction in electrical equipment efficiency, interference in protection systems and grid. Hence power quality problem become a major concern for both power companies and customers. To quantify the problems, D-STATCOM is used. Distributed Static Synchronous Compensator (DSTATCOM), which consists of an IGBT-based voltage source inverter, uses advanced power switches to provide fast response and flexible voltage control at the connection for power quality improvement in distribution systems.

Advantages of D-STATCOM:

1. Flexible voltage control

2. Improvement in Power factor

3. Harmonic contents can be reduced

4. Fast response

EAF is described in Section II. Section III comprises of D-statcom and its control strategy. Section IV describes the simulation results. Section V describes about the conclusion.

\section{ARC FURNACES}

Its structure resembles to that of two electrodes with a charge placed inside a heating chamber. When the air-gap between the electrodes is subjected to maximum voltage stress, contacts between them ionized to make the flow of current which results in the form of arc. Since the electrical arc is a nonlinear and time varying phenomenon, description of its behaviour in the time domain is easier than in the frequency domain. There are different numbers of models for EAF such as

1. Harmonic voltage source model

2. Time domain model

3. Frequency model

Time domain model is proposed here. Time domain models can be classified into V-I Characteristic (VIC), and Equivalent Circuit Methods (ECM). Based on the V-I characteristic of arc furnace, which is derived from the relationship between arc voltage and arc current VIC method is used. This method is widely used for modelling the static and the dynamic operation of EAF. This paper proposes a new model named as Hyperbolic model of EAF in the time domain. The proposed model of EAF is explained with a good approximation without need of the initial conditions of the EAF[1]. Also, it is used to describe different operating situation of the EAF and power system. The accuracy of the load model is increased by establishing random and sinusoidal noises to have a new model. An EAF flicker model based on a hyperbolic model is simulated in the first part. In the second part, the DSTATCOM with direct and indirect control is simulated. 


\section{Hyperbolic Model:}

Basically there are two models such as Static and Dynamic model. Simulation of arc is the important issue in the modelling of EAF. There are several methods used to describe the electric arc. Here, Hyperbolic model of EAF is discussed and simulated in the first part [4] and D-statcom with indirect,direct,Hysteresis control is proposed and simulated.

The below figure (Fig2.1) represents the VI characteristics of EAF and actual linear piecewise model [1, 2, 3 and 5]. But the Hyperbolic model discussed is a non-linear one and is modelled according to equation (2.1) \& (2.2).

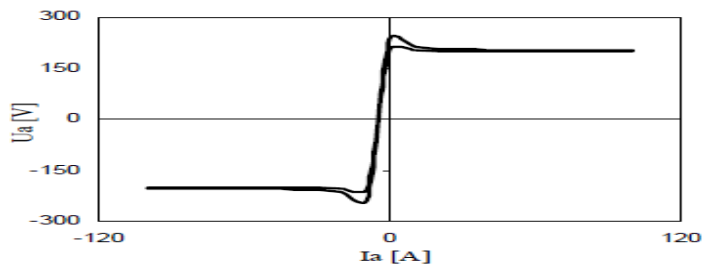

\section{Characetristics of EAF - Fig2.1}

For static model the VIC of the EAF is considered to be in the form of $\mathrm{V}=\mathrm{V}$ (i) and it can described as: $\mathrm{V}(\mathrm{i})=\mathrm{V}_{\mathrm{at}}+(\mathrm{C} / \mathrm{D})+\mathrm{i}$

Where, $\mathrm{V}$ - arc voltage, $\mathrm{i}$ - arc current per phase. $\mathrm{V}_{\mathrm{at}}$ - threshold magnitude. $\mathrm{V}_{\mathrm{at}}$ is the magnitude of threshold voltage to which the voltage approaches as current increases. Its value depends on the arc length which is defined by constants $\mathrm{C}$ and D which are of arc power and arc current respectively. Dynamic EAF model is required for real time analysis of the effect of the arc. The dynamic arc characteristic is simulated by varying arc conductance. In general, the variation is of random nature. Two types of variation are considered for the studysinusoidal and random. In order to study the effect of voltage flicker on the system of EAF, Vat is varied sinusoidally and randomly. In this regard Vat is modulated as follows:

The sinusoidal variation is assumed as:

$\mathrm{V}_{\mathrm{at}}(\mathrm{t})=\mathrm{V}_{\mathrm{at} 0}\left[1+\mathrm{m} \cdot \sin \left(\omega_{\mathrm{f}} \mathrm{t}\right)\right]$

Where, $\mathrm{m}$ is modulation index and $\omega_{\mathrm{f}}$ is a flicker frequency. For random flicker generation $\mathrm{V}_{\mathrm{at}}$ is modulated with a random signal with the mean of zero. Thus $\mathrm{V}_{\text {at }}$ is written as:

$\mathrm{V}_{\mathrm{at}}(\mathrm{t})=\mathrm{V}_{\mathrm{at0}}[1+\mathrm{m} \cdot \mathrm{N}(\mathrm{t})]$

where, $\mathrm{N}(\mathrm{t})$ is a band limited white noise with zero mean and variance of one.

\section{Problems of EAF:}

Due to the usage of EAF, it creates problems as follows:

1. Harmonics

2. Voltage Fluctuations

3. Flickering

4. Low power factor

Hence the other loads connected also gets affected and also the source voltage. Hence EAF is considered to be the main cause of power quality degradation. Therefore we have to find a solution to improve power quality because at the load point production process gets more complicated and requirement of a bigger reliability level will occur. Hence we have to avoid this by providing energy without interruptions, without harmonic distortion and keeping the voltage in a very narrow margin. The devices which can fulfil these requirements are the Custom Power devices among wihch D-statcom is proposed here.

\section{III. .PROPOSED METHOD:}

IEEE defines Static Synchronous Generators as self-commutated switching power converters supplied from an appropriate electric energy source and operated to produce a set of adjustable multiphase voltages, which may be coupled to an ac power system for the purpose of exchanging independently controllable real and reactive power.

D-STATCOM compensates by generating or absorbing reactive power by using power electronic switching converters. However, in STATCOM systems, the reactive power is determined by the switching converter part and reactive power can be kept constant irrespective of the supply voltage fluctuations. STATCOM systems are used in distribution and transmission systems for different purposes. STATCOMs are used in transmission systems to control reactive power and to supply voltage support to buses. STATCOM is 
installed in distribution systems or near the loads to improve power factor and voltage regulation. This type of STATCOM is called D-STATCOM.

\section{DSTATCOM}

(Distributed static Synchronous compensator) is the proposed model to improve the power quality[2]. Multifunctions preformed by D-statcom are:

- Voltage regulation and compensation of reactive power;

- Correction of power factor and

- Elimination of current harmonics. Here, such a device is employed to provide continuous voltage regulation using an indirectly controlled converter[3]. Single diagram of D-statcom is shown in Fig3.1

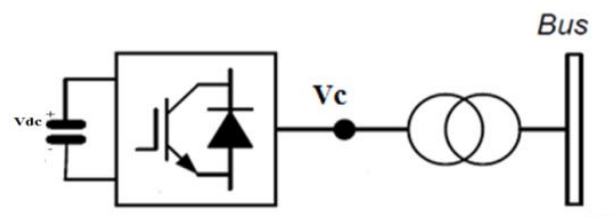

Single diagram of D-statcom - Fig3.1

\section{Description of the proposed system:}

The main circuit of the DSTATCOM system with Arc Furnace load connected to 3-phase, 3-wire distribution system together with the measurements needed by the control system is shown in Fig.(3.2). The Arc Furnace is modelled as a Hyperbolic model. Under operation without D-statcom, EAF results in fluctuating load currents and voltage fluctuation at PCC. To compensate the fluctuating load currents and to mitigate it, algorithms based upon Indirect control (d-q theory), Direct control (P-Q theory) [5], Hysteresis Controller is proposed.

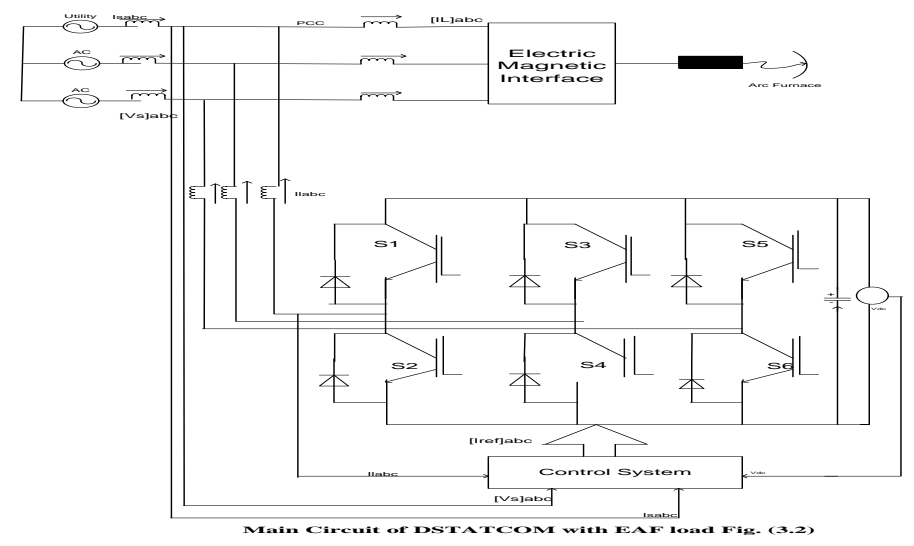

Compensation strategies: A.Direct control of EAF using D-statcom:

Instantaneous reactive power theory (P-Q theory):

$\mathrm{P}-\mathrm{Q}$ theory transforms the three phase system of voltages and currents from phase co-ordinates to $0-\alpha$ $\beta$ coordinates by means of Clark-Concordia transformation, which is represented by the following matrix equation (3.1) and (3.2).

$\left[\begin{array}{l}V_{0} \\ V_{\alpha} \\ V_{\beta}\end{array}\right]=\sqrt{2 / 3}\left[\begin{array}{ccc}1 / \sqrt{2} & 1 / \sqrt{2} & 1 / \sqrt{2} \\ 1 & -1 / 2 & -1 / 2 \\ 0 & \sqrt{3} / 2 & -\sqrt{3} / 2\end{array}\right]\left[\begin{array}{l}V_{a} \\ V_{b} \\ V_{c}\end{array}\right]$
$\left[\begin{array}{l}I_{0} \\ I_{\propto} \\ I_{\beta}\end{array}\right]=\sqrt{2 / 3}\left[\begin{array}{ccc}1 / \sqrt{2} & 1 / \sqrt{2} & 1 / \sqrt{2} \\ 1 & -1 / 2 & -1 / 2 \\ 0 & \sqrt{3} / 2 & -\sqrt{3} / 2\end{array}\right]\left[\begin{array}{l}I_{a} \\ I_{b} \\ I_{c}\end{array}\right]$

In the case of three-phase three-wire systems $\mathrm{V}_{\mathrm{o}}=0$ and $\mathrm{i}_{\mathrm{o}}=0$. In the new co-ordinate system using stationary orthogonal reference frame theory, the instantaneous real and imaginary powers are expressed by the following matrix equation (3.3) \& (3.4), which finally allows expression of currents as a function of the power quantities. 
$\left[\begin{array}{l}p \\ q\end{array}\right]=\left[\begin{array}{cc}V_{\alpha} & V_{\beta} \\ -V_{\beta} & V_{\alpha}\end{array}\right]\left[\begin{array}{l}I_{\alpha} \\ I_{\beta}\end{array}\right]$

$\left[\begin{array}{l}I_{\propto} \\ I_{\beta}\end{array}\right]=\frac{1}{V_{\propto}^{2}+V_{\beta}^{2}}\left[\begin{array}{cc}V_{\propto} & V_{\beta} \\ -V_{\beta} & V_{\alpha}\end{array}\right]\left[\begin{array}{l}p \\ q\end{array}\right]$

The control algorithm based on pq theory compensation is outlined here under. The three phase source voltages $\left[\mathrm{V}_{\mathrm{sa}}, \mathrm{V}_{\mathrm{sb}}, \mathrm{V}_{\mathrm{sc}}\right]$ are transformed to stationary orthogonal reference frame variables $\left[\mathrm{V}_{\mathrm{s} \alpha}, \mathrm{V}_{\mathrm{s} \beta}\right]$. Reference currents $\left(\mathrm{i}_{\alpha}{ }^{*}, \mathrm{i}_{\beta} *\right.$ ) are evaluated based on equation (3.4) by using $\mathrm{V}_{\mathrm{s} \alpha}, \mathrm{V}_{\mathrm{s} \beta}$ and $\mathrm{p}_{\text {ref }}$ and $\mathrm{q}_{\mathrm{ref}}$. The instantaneous active power $\left(\mathrm{p}_{\text {ref }}\right)$ for maintaining dc link voltage constant is obtained by comparing actual dc link voltage with a preset value and by processing the error voltage through a PI controller.

The instantaneous reactive power reference $\left(\mathrm{q}_{\mathrm{ref}}\right)$ is set to zero. With the evaluated reference currents in orthogonal frame, the actual source currents in the same frame are compared and processed through PI controllers and reference voltages are obtained in stationary frame which are transformed to abc frame using Clark's reverse transformation for generating gate pulses for the IGBT based voltage source inverter.

\section{B. Indirect control of EAF using D-Statcom:}

\section{Synchronous reference frame theory: (d-qtheory)}

The synchronous reference theory is based on the transformation of the stationary reference frame three phase variables $(\mathrm{a}, \mathrm{b}, \mathrm{c})$ to synchronous reference frame variables $(\mathrm{d}, \mathrm{q}, \mathrm{o})$ whose direct (d)and quadrature (q) axes rotate in space at the synchronous speed $\omega_{\mathrm{e}} . \omega_{\mathrm{e}}$ is the angular electrical speed of the rotating magnetic field of the three phase supply, given by $\omega_{\mathrm{e}}=2 \pi \mathrm{f}_{\mathrm{s}}$, where $\mathrm{f}_{\mathrm{s}}$ is the frequency of the supply.

If $\theta$ is the transformation angle, then the current transformation from abc to d-q- 0 frame is defined as in the following equations:

$$
\left[\begin{array}{c}
I_{d} \\
I_{q} \\
I_{0}
\end{array}\right]=\sqrt{2 / 3}\left[\begin{array}{ccc}
\cos \theta & \cos \left(\theta-\frac{2 \pi}{3}\right) & \cos \left(\theta+\frac{2 \pi}{3}\right) \\
\sin \theta & \sin \left(\theta-\frac{2 \pi}{3}\right) & \sin \left(\theta+\frac{2 \pi}{3}\right) \\
1 / \sqrt{2} & 1 / \sqrt{2} & 1 / \sqrt{2}
\end{array}\right]\left[\begin{array}{l}
I_{a} \\
I_{b} \\
I_{c}
\end{array}\right]
$$

\section{Hysteresis Controller:}

Using this control, rapid switching of each switch is done by using the comparison of the measurement of D-Statcom current with the reference current. Basic principle behind this is to produce the switching signals by using the comparison of error signal with the fixed value of hysteresis bandwidth.

\section{Advantages:}

- Simple Technique

- Robust

- Fast Response

- Good stability

\section{Generation of Switching signals using Hysteresis controller:}

Reference current signals are generated by using $\mathrm{d}$-q transformation. Here the three phase current variables are transformed into synchronous reference frame to synchronize the ac main voltage with the reference frame variables. The above transformation is done by converting the three phase supply variables into $\mathrm{d}-\mathrm{q}$ variable by using the matrix equation (3.5)

$$
\left[\begin{array}{c}
I_{d} \\
I_{q} \\
I_{0}
\end{array}\right]=\sqrt{2 / 3}\left[\begin{array}{ccc}
\cos \theta & \cos \left(\theta-\frac{2 \pi}{3}\right) & \cos \left(\theta+\frac{2 \pi}{3}\right) \\
\sin \theta & \sin \left(\theta-\frac{2 \pi}{3}\right) & \sin \left(\theta+\frac{2 \pi}{3}\right) \\
1 / \sqrt{2} & 1 / \sqrt{2} & 1 / \sqrt{2}
\end{array}\right]\left[\begin{array}{l}
I_{a} \\
I_{b} \\
I_{c}
\end{array}\right]
$$

Reference currents produced by transformation are compared with the D-Statcom current which gives the output as error signal. This signal is compared with the hysteresis bandwidth [6] to generate the switching signals. Tolerable bandwidth is taken as $\pm 2 \%$ of reference value of current. Upper switch of that leg will be turned ON, but the lower switches will be in OFF condition when the value of the phase current exceeds the 
upper bandwidth. Reverse operation will take place when the phase current value falls below the lower bandwidth.

\section{SIMULATION RESULTS}

This deals about the simulation results and THD comparison for different controls of D-Statcom. Simulated THD output was tabulated and viewed in bar chart Fig. 4.1 shows the EAF voltage and current. Fig 4.2 shows the source output voltage and current without D-statcom. Fig. 4.3 shows the THD output without Dstatcom. Fig 4.4 shows the output of source output voltage and current with Direct control of D-statcom. Fig 4.5 shows the THD output of direct control using D-statcom. Fig 4.6 and Fig.4.7shows the instantaneous active and reactive power with direct control of d-statcom. Fig. 4.8 shows the source output voltage and current using Indirect control of D-statcom. Fig 4.9 shows the THD output of Indirect control of D-statcom. Fig 4.10 and Fig.4.11 shows the instantaneous active and reactive power with Indirect control of d-statcom. Fig 4.12 shows the output of source output voltage and current with Hysteresis controller of D-statcom. Fig 4.13 shows the THD output of Hysteresis control using D-statcom. Fig 4.14 and Fig.4.15 shows the instantaneous active and reactive power with Hysteresis controller of d-statcom.
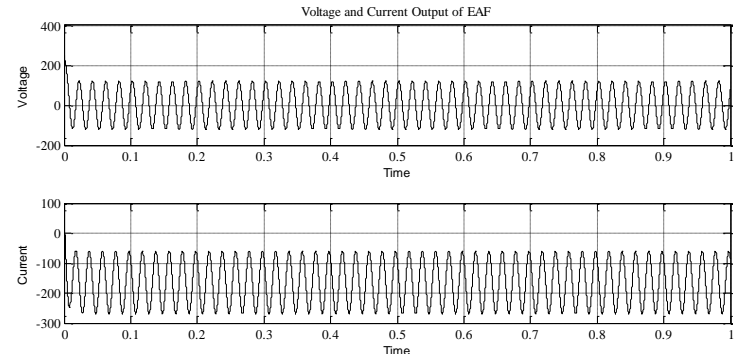

3 Phase Eaf Voltage And Current Output- Fig (4.1)
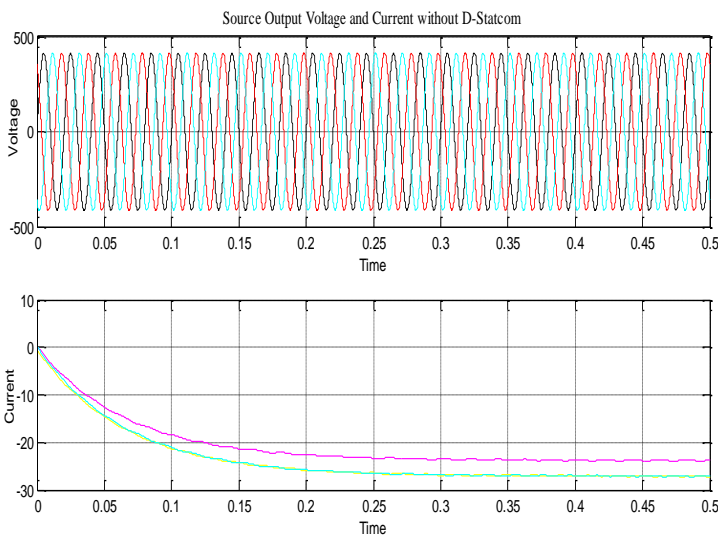

3 Phase Source Output Without D-Statcom- Fig 4.2

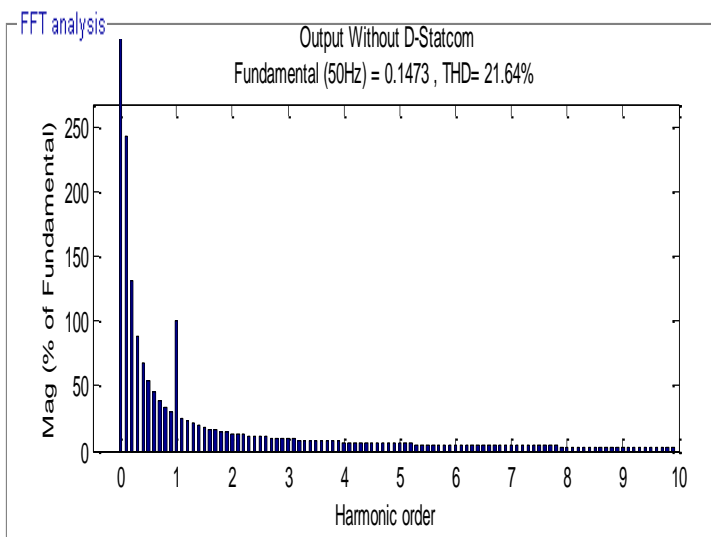

Thd Output Without D-Statcom- Fig 4.3 

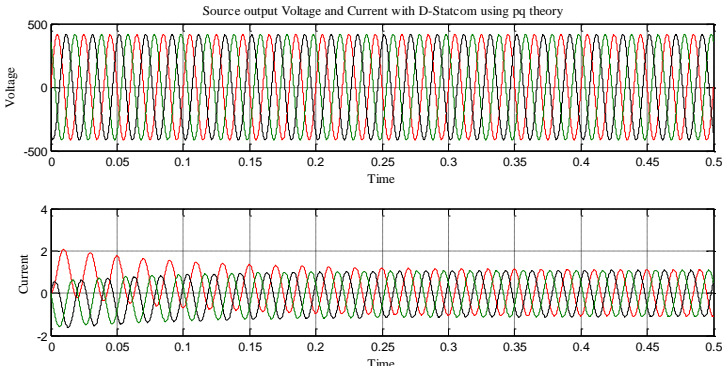

3 Phase Source Output With Direct Control Of D-Statcom- Fig 4.4

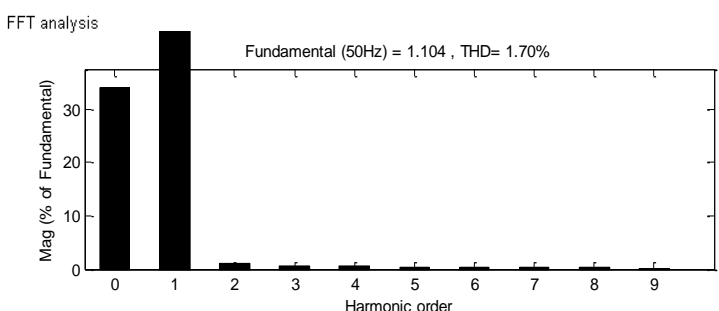

Thd Output With Direct Control Of D-Statcom - Fig 4.5

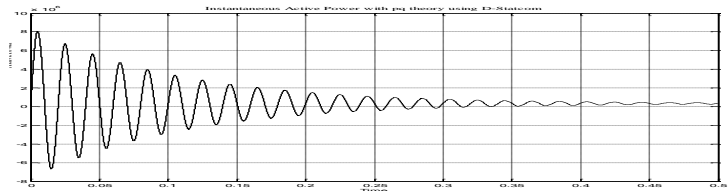

Instantaneous Active Power Output With Direct Control Of D-Statcom - Fig 4.6

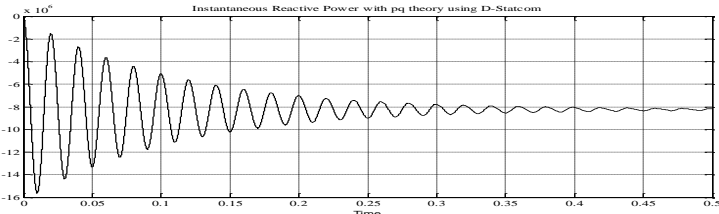

Instantaneous Reactive Power Output With Direct Control Of D-Statcom - Fig 4.7
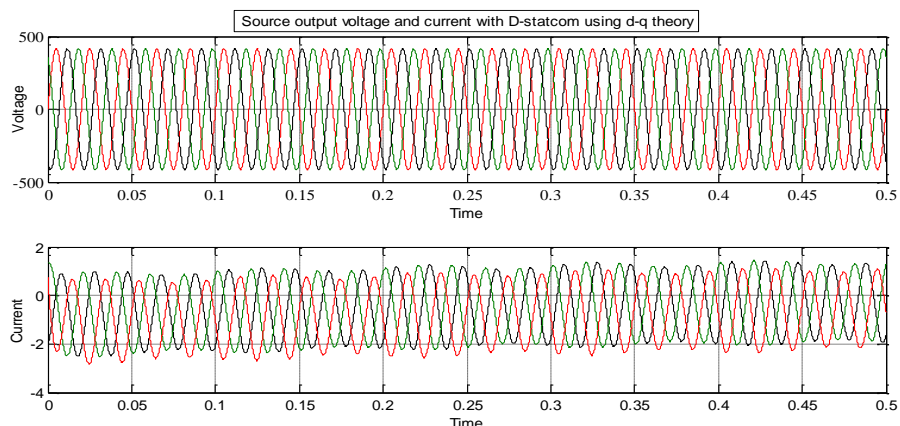

3 Phase Source Output With Indirect Control Of D-Statcom - Fig 4.8

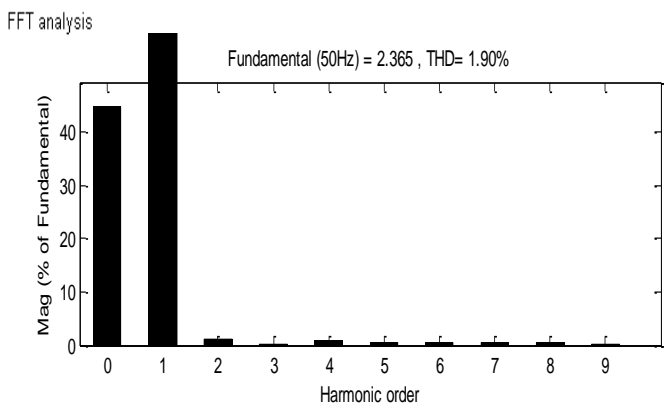

Thd Output With Indirect Control Of D-Statcom - Fig 4.9 


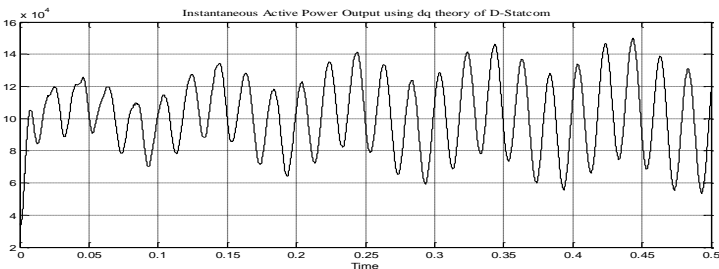

Instantaneous Active Power Output With Indirect Control Of D-Statcom - Fig 4.10

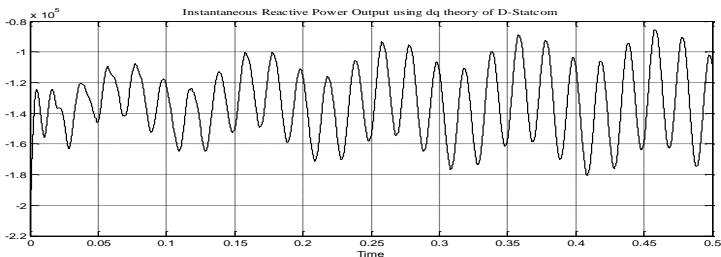

Instantaneous Reactive Power Output With Indirect Control Of D-Statcom - Fig 4.11
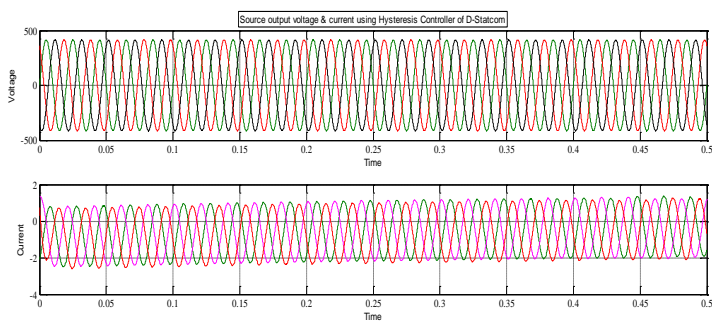

3 Phase Source Output With Hysteresis Controller Of D-Statcom- Fig 4.12

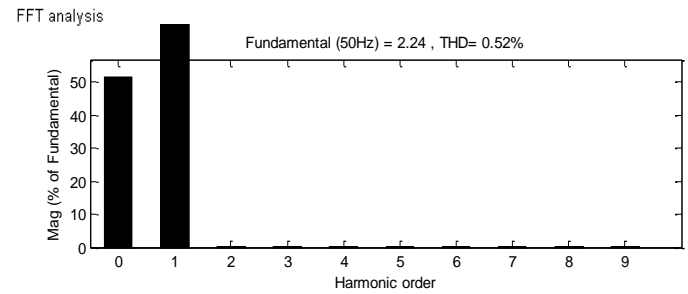

Thd Output With Hysteresis Controller Of D-Statcom - Fig 4.13

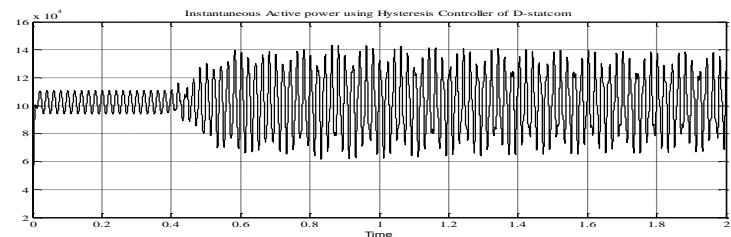

Instantaneous Active Power Output With Hysteresis Controller Of D-Statcom-Fig 4.14

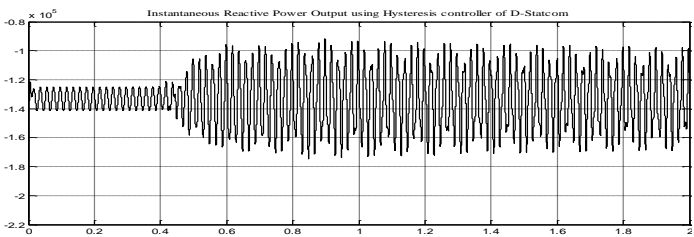

Instantaneous Reactive Power Output With Hysteresis Controller Of D-Statcom -Fig 4.15

THD EVALUATION using D-Statcom-Table - 4.1
\begin{tabular}{|l|l|l|}
\hline S1.NO & Theory & THD \\
\hline 1. & DQ theory & $1.90 \%$ \\
\hline 2. & PQ theory & $1.70 \%$ \\
\hline 3. & Hysteresis controller & $0.52 \%$ \\
\hline 4. & Without D-Statcom & $21.64 \%$ \\
\hline
\end{tabular}




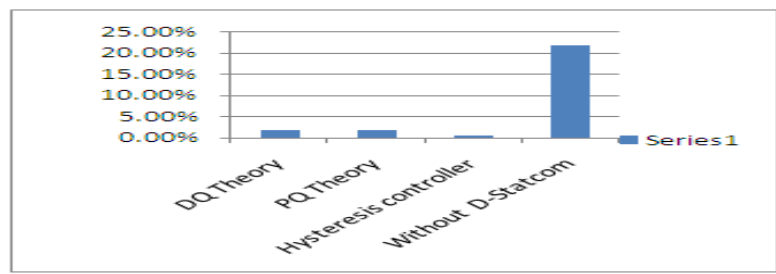

\section{CONCLUSION}

Electric Arc furnace used in industries is concluded as one of the major power quality degradation. Compensation technique provided with the Direct, Indirect control and Hysteresis controller of D-Statcom is discussed here. In this, D-STATCOM controller is derived by using orthogonal reference frame theory, synchronous reference frame theory and Hysteresis controller. The model is simulated using Matlab simulink and D-STATCOM controller's performance is evaluated using Direct, Indirect and Hysteresis control for Total Harmonic Distortion. All the controllers are proven to be effective with improved response. From the results obtained for Total Harmonic Distortion, Hysteresis control of D-statcom is the best one. Future scope is to simulate the D-statcom with the different control technique to have further reduction in harmonics for the new model of EAF.

\section{REFERENCES}

[1]. K.Anuradha, B.P.Muni "Modeling of Electric Arc Furnace \& Control Algorithms for voltage flicker mitigation using DSTATCOM", IEEE 2009

[2]. Y. Najafi Sarem, M. H. Amrollahi, M. Babanejad, Sh. Mounesirad \& M. Abbasi Layegh and Davood habibinia, "Electric Arc Furnace Power Modeling for STATCOM Controller Application", International Symposium on Power Electronics,Electrical Drives, Automation and Motion 2010

[3]. A. Alzate, A. Escobar, J. J. Marulanda, "Application of a D-STATCOM to Mitigate Arc Furnaces Power Quality Problems", I EEE Trondheim Power Tech, 2011.

[4]. C. Bhonsle, R.B. Kelkar, "Simulation of Electric Arc Furnace Characteristics for Voltage Flicker study using MATLAB", International Conference on Recent Advancements in Electrical, Electronics and Control Engineering, 2011

[5]. M .NagaRaju, Dr.K .Anuradha, Dr. G. R. K. Murthy, A.Santha Kumari,” Voltage flicker mitigation by DSTATCOM for voltage source Arc furnace model" IEEE 2011

[6]. Genzhong, "Combined hysteresis current-controlled PWM inverter and robust control for a permanentmagnet synchronous motor", IEEE 2011

[7]. NareshK.Kumari, "Comparitive Evaluation of D-statcom Control Algorithms for Load compensation",IEEE 2012 